\title{
The study of the ground plane effect on a Multiband PIFA Antenna by using Genetic Algorithm and Particle Swarm Optimization
}

\author{
L. WAKRIM, S.IBNYAICH, \\ I2SP Team, Faculty of science semlalia, Marrakech-Morocco \\ Layla.wakrim@gmail.com, ibnyaichsaida@gmail.com \\ M.M.HASSANI \\ I2SP Team, Faculty of science semlalia, Marrakech-Morocco \\ hassani@uca.ac.ma
}

\begin{abstract}
The ground plane plays an important role on the performance of a planar inverted-F antenna (PIFA). In this regard, the ground plane modification using slots is proposed in this research to obtain a dual band antenna for WiMAX application.

Popular optimization techniques, as genetic algorithm (GA) and particle swarm optimization (PSO), were used to design the shape of the ground plane in order to improve the bandwidth and to achieve dual band antenna instead of single band antenna.

The proposed method divides the overall ground plane into different cells. Through this technique it is possible to obtain a dual band antenna reduced by more than $50 \%$, thereby reducing the overall ground plane.

Both GA and PSO designs are provided. This new method shows many advantages over PIFA antenna in terms of performance and weight.
\end{abstract}

Index Terms-PIFA Antenna, Genetic algorithm, Particle swarm optimization, WiMAX, Bandwidth.

\section{INTRODUCTION}

With the rapid progress in the wireless communication, there is an increase demand for antenna solutions that provide multi band, small size, low cost, and high performance [1]. Therefore, new antennas should be developed providing larger bandwidth and at the same time smaller dimensions. Planar Inverted-F Antenna (PIFA) is the most widely used antenna owing to its low profile, simple structure and ease of fabrication, and primarily its high efficiency and wideband characteristic [2].Because of all these interesting characteristics, PIFAs are extremely attractive to be used in multiband applications, and growing research activity is being focused on them. The wireless communication device provides the ability to integrate multiband. Therefore, a dual or multiband antenna is attractive in many commercial applications as it is designed to have a single radiator with a capability to transmit and receive multiple frequencies [3].

The objective of this study is to demonstrate a very effective method of bandwidth enhancement and multiband for PIFA antenna. Our research provides a dual band PIFA antenna and maximizes the bandwidth while keeping its overall size small. While doing so, the genetic algorithm and Particle 
swarm optimization techniques (GA and PSO) combined with slotted ground plane have been analyzed to find a better antenna's performance.

The GA is considered to be a robust and stochastic search method modeled on the principles and concepts of nature selection and evolution because no restrictions on the solution space are made during the process. The power of this algorithm comes from its ability to exploit historical information structures from previous solution guesses in an attempt to increase performance of future solution structures [4].

On the other hand, methods of global optimization as the particle swarm optimization (PSO) were introduced to the electromagnetic (EM) community to find optimal solution for a complex electromagnetic problem [5].

The PSO was originally introduced by J. Kennedy et al. (1995) [6], it is a robust stochastic evolutionary computation technique based on the movement and intelligence of swarm [7]. The PSO has been applied to many EM applications, such as multiband and wide-band patch antenna designs [8]-[9], monopole antenna [10] and fractal antenna design [11].

There is a lot of interest in discovering new techniques in order to achieve smaller, wideband and multiband antennas. Usually, optimizing the antenna geometry is the common way to design an antenna to get good performance as shown in [12]-[13]-[14]. It has been shown in [15]-[17] that the slots on the ground plane play a very important role in the improvement of bandwidth of the PIFA antenna. On the other hand, [18] shows the influence of the T-shaped slot on the ground Plane. In [19], by slotting the ground plane with V-shaped slots and adjusting the parameters of slots, two more resonances were excited and the bandwidth is increased. Finally, the introducing of an open slot on the ground plane for increasing operational bandwidth of a compact planar inverted F antenna (PIFA) was described in [20].

Therefore, the purpose of the present paper is to reach a dual band and smaller PIFA antenna by adding several slots on the ground plane, their locations and dimensions are obtained by using genetic algorithm (GA) and particle swarm (PS) optimization techniques, the objective is to show how this solution can also provide a bandwidth enhancement.

The paper is divided as follows: after an introduction, section 2 shows the initial antenna dimensions and configuration, then section 3 describes the used method in order to get good results and section 4 shows the simulation results obtained for the proposed designs firstly by GA then by PSO. Finally, section 5 is a conclusion for this research.

\section{A. Genetic Algorithm overview}

The genetic algorithm (GA) is the most popular of the evolutionary methods in the electromagnetic community. Relying on Darwin's original thoughts it has been argued that life in this world in all its diverse was evolved by natural selection and adaptation processes controlled by the survivability of the fittest species. With this acceptance has come, the temptation that perhaps one might be able to 
utilize natures, "selection and adaptation engine" and apply it to the solution of engineering problems via the applications of the Genetic Algorithm (GA) [21].

In general, a GA must be able to perform six basic steps [22]:

1. Encode the solutions,

2. Create a string of the gene to form chromosome,

3. Generate an initial population,

4. Evaluate fitness values to individuals in the population,

5. Select parent solutions for breeding,

6. Perform recombination and mutation to produce members of the next generation.

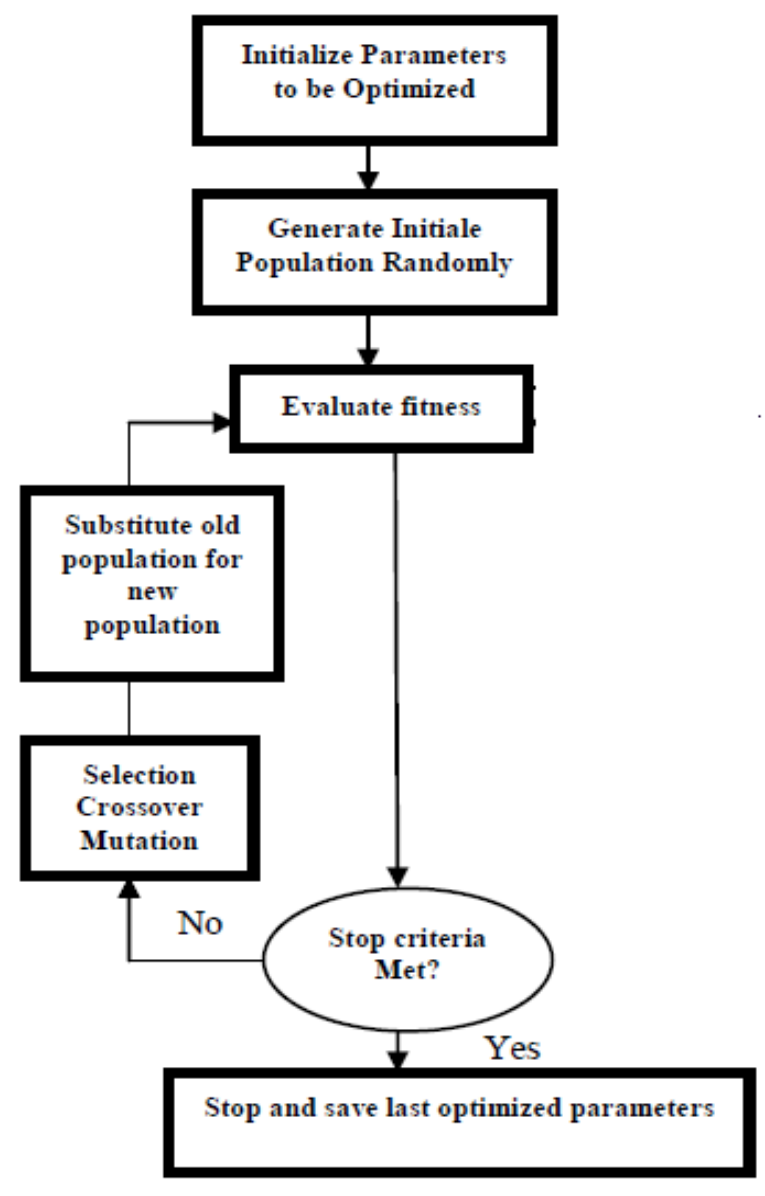

Fig.1: Genetic algorithm block diagram

These performance requirements lead to the existence of three phases in a typical genetic-algorithm optimization. These phases are (1) initiation, (2) reproduction, and (3) generation replacement. In the simple, typical genetic-algorithm optimizer of Fig.1, initiation consists of filling an initial population with a predetermined number of encoded, usually randomly created, parameter strings, or chromosomes. Each of these chromosomes represents an individual prototype solution or, simply, an individual. The set of individuals is called the current generation. Each individual in the set is assigned a fitness value by evaluating the fitness function for each individual. The reproduction phase 
produces a new generation from the current generation. In reproduction, a pair of individuals is selected from the population to act as parents. The parents undergo crossover and mutation, thereby producing a pair of children. These children are then placed in the new generation. The selection, crossover, and mutation operations are repeated until enough children have been generated to fill the new generation [23].

\section{B. Particle Swarm Optimization}

Recently, the PSO technique has been successfully applied to the design of antennas and microwave components. The results proved that this method is powerful and effective for optimization problems [24]. It is similar to genetic algorithm [25].

The PSO algorithm is an evolutionary algorithm capable of solving difficult multidimensional optimization problems in various fields. Fig. 2 shows the flowchart of a PSO algorithm.

As an evolutionary algorithm, the PSO algorithm depends on the social interaction between independent particles, during their search for the optimum solution. A population of particles is randomly generated initially. Each particle represents a potential solution and has a position represented by a position vector $\overrightarrow{x_{1}}$. A swarm of particles moves through the problem space; with the moving velocity of each particle represented by a velocity vector $\overrightarrow{v_{1}}$. Each particle keeps track of its own best position, which is associated with the best fitness it has achieved so far in a vector $\overrightarrow{\mathrm{p}_{1}}$. Furthermore; the best position among all the particles obtained so far in the population is kept track of as $\overrightarrow{p_{g}}[26]$.The particle's velocity update and position update are the main PSO operators, which can be expressed as [27]-[28]:

$$
\begin{aligned}
& \overrightarrow{\mathrm{v}_{1}}(\tau+1)=\omega \overrightarrow{\mathrm{v}_{1}}(\tau)+\mathrm{c}_{1} \gamma_{1}\left(\overrightarrow{\mathrm{p}_{1}}(\tau)-\overrightarrow{\mathrm{x}_{1}}(\tau)\right)+\mathrm{c}_{2} \gamma_{2}\left(\overrightarrow{\mathrm{p}_{\mathrm{g}}}(\tau)-\overrightarrow{\mathrm{x}_{1}}(\tau)\right) \\
& \overrightarrow{\mathrm{x}_{1}}(\tau+1)=\overrightarrow{\mathrm{x}_{1}}(\tau)+\overrightarrow{\mathrm{v}_{1}}(\tau+1)
\end{aligned}
$$

where $c_{1}$ and $c_{2}$ are acceleration constants and $\gamma_{1}$ and $\gamma_{2}$ are uniformly distributed random numbers in $[0,1]$. The term $\overrightarrow{v_{1}}$ is limited to its bounds. If the velocity violates this limit, it is set to its proper limit. $\omega$ is the inertia weight factor and in general, it is set according to the following equation:

$\omega=\omega_{\max }-\frac{\omega_{\max }-\omega_{\min }}{\mathrm{T}} \cdot \tau$

Where $\omega_{\max }$ and $\omega_{\min }$ is maximum and minimum value of the weighting factor respectively. $\mathrm{T}$ is the maximum number of iterations and $\tau$ is the current iteration number. 


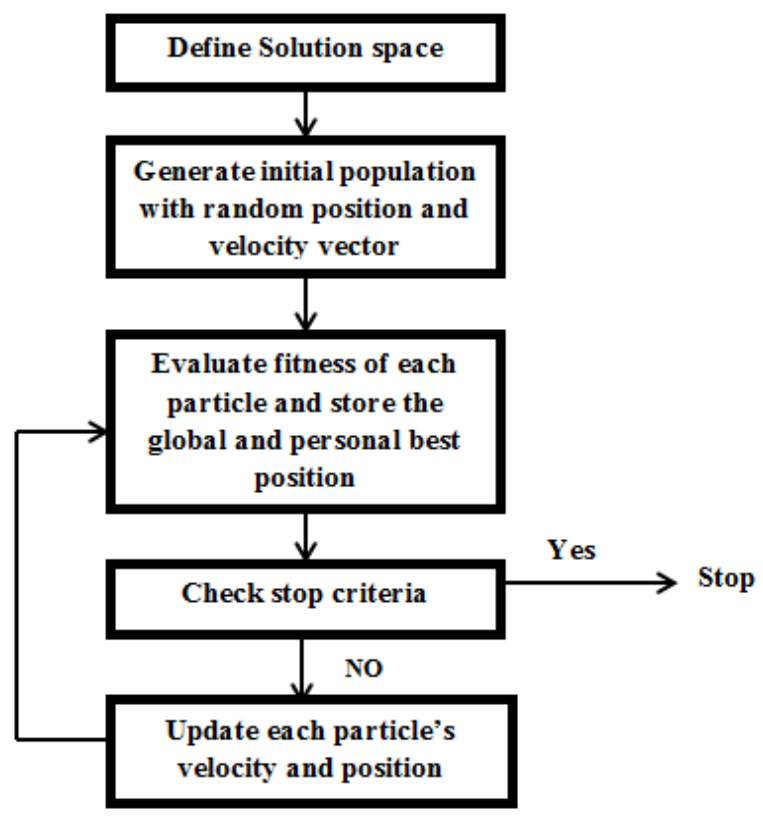

Fig.2: Flowchart of a PSO algorithm

\section{PIFA ANTENNA CONFIGURATION}

Initially, the geometry parameters of the PIFA antenna can be approximately predicted, using the following formula [29]

$$
\mathrm{f}_{\mathrm{r}}=\frac{\mathrm{C}}{4(\mathrm{~L}+\mathrm{W})}
$$

Where $\mathrm{C}$ is the speed of light; $\mathrm{W}$ and $\mathrm{L}$ are the width and length of the radiating element, respectively, $\mathrm{f}_{\mathrm{r}}$ is the resonant frequency.

The geometry of the proposed antenna without slots is shown in Fig. 3. It is composed of ground plane; top patch is constructed of copper with a $0.2 \mathrm{~mm}$ of thickness, feeding pin, and shorting pin connecting to the ground plane. The dielectric material selected for the design is FR4 which has dielectric constant of $\mathrm{er}=4.4$ and a height of $0.5 \mathrm{~mm}$.It is fed by $50 \mathrm{ohm}$ microstrip line. The dimensions of the antenna are shown in Table I and the specifications of the key elements for the design of the rectangular planar inverted -F antenna are listed in Table II.

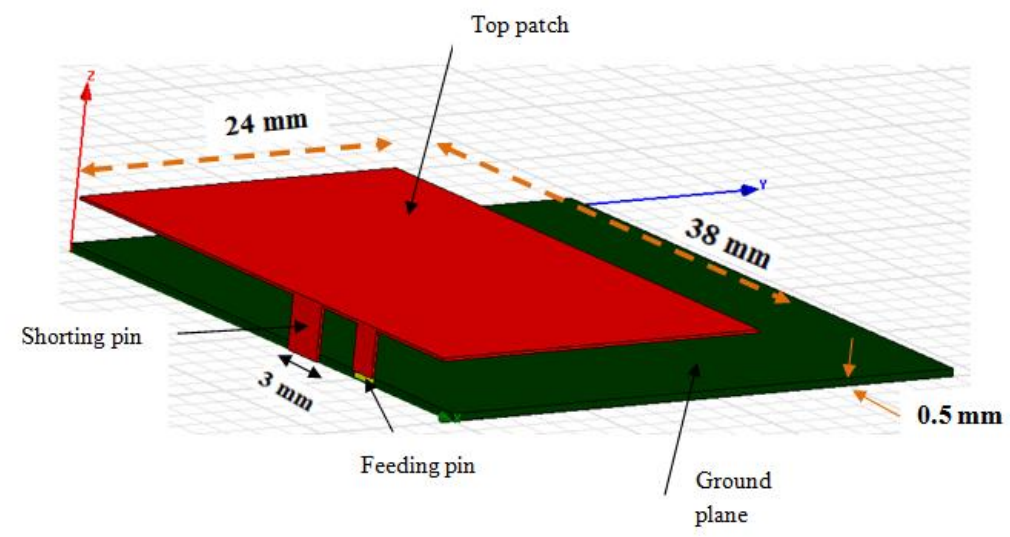

Fig.3: 3D view geometry of PIFA antenna 
Journal of Microwaves, Optoelectronics and Electromagnetic Applications, Vol. 15, No. 4, December 2016298 DOI: http://dx.doi.org/10.1590/2179-10742016v15i4626

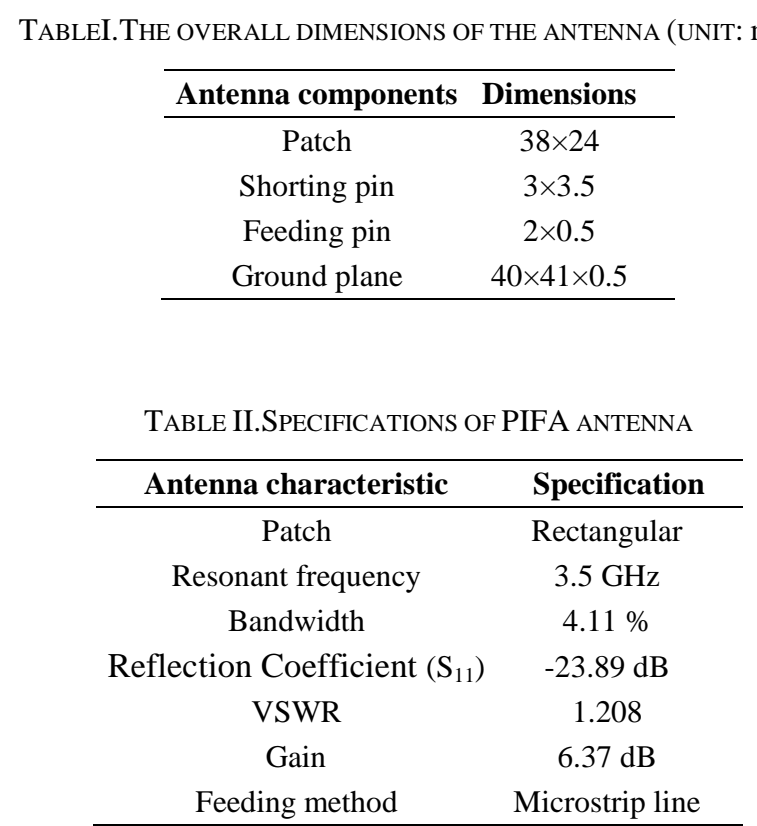

This PIFA antenna will be used as reference antenna for the optimization process in this paper.

\section{METODOLOGY}

In this study, genetic algorithm (GA) and particle swarm optimization (PSO) were used to design the ground plane geometry in order to achieve multiband PIFA antenna with largest bandwidth.

The ground plane area $\left(40 \times 41 \mathrm{~mm}^{2}\right)$ is divided into small cells as shown in Fig. 4 where each cell can be assigned either conducting or non-conducting properties. The size of a cell was taken equal to $5 \times 5 \mathrm{~mm}^{2}$ in order to achieve better results.

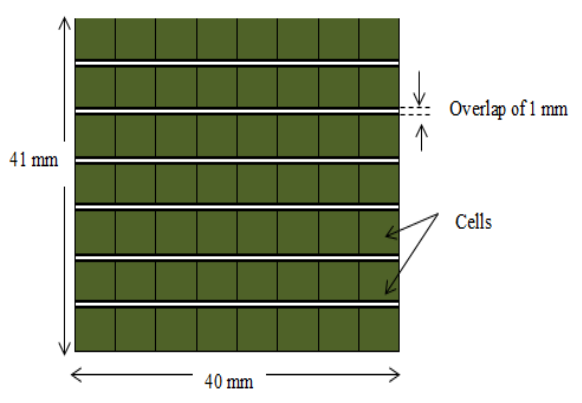

Fig.4: Gridded ground plane

The ground plane is fragmented into 56 cells so as to overlap between adjacent cells with a $1 \mathrm{~mm}$ width in order to search for the best solution of conducting cells. There are only two possible values, binary coding is used. If a cell is existing, then the corresponding gene is assigned " 1 " and if a cell non-existent considered as slot, the gene takes the " 0 " value.

The fitness function is the summation of reflection coefficient values at WiMAX band's frequencies. The fitness function $\mathrm{F}$ which is minimized in the search for the optimum solution is written as: 
Journal of Microwaves, Optoelectronics and Electromagnetic Applications, Vol. 15, No. 4, December 2016299 DOI: http://dx.doi.org/10.1590/2179-10742016v15i4626

$$
\mathrm{F}=\sum_{i=1}^{N} S 11(f(i)) / \mathrm{N}
$$

In the equation above, $\mathrm{f}(\mathrm{i})$ is the sampling frequency, $\mathrm{N}$ is the number of the sample. $\mathrm{S}_{11}$ presents the reflection coefficient.

The purpose here is to find an optimized ground plane with GA and PSO that achieves a reflection coefficient less than $-10 \mathrm{~dB}$ in the frequency bands given by WiMAX.

To achieve the objective, the GA and PSO optimizations are applied to define the cells on the ground plane that give multiband antenna and large bandwidth.

The control parameters in the optimization using GA are as follows:

-Population size: 30

- Maximum number of generations: 200

-Crossover: two points, performed with probability of $50 \%$

- Mutation: is Gaussian mutated in $100 \%$

- Selection: Roulette method.

On the other hand, the number of particles in a swarm is set to be 30 and the maximum number of iterations is set as 200 .

The optimization process is implemented as shown in Fig.5. The two software programs MATLAB and HFSS are linked.

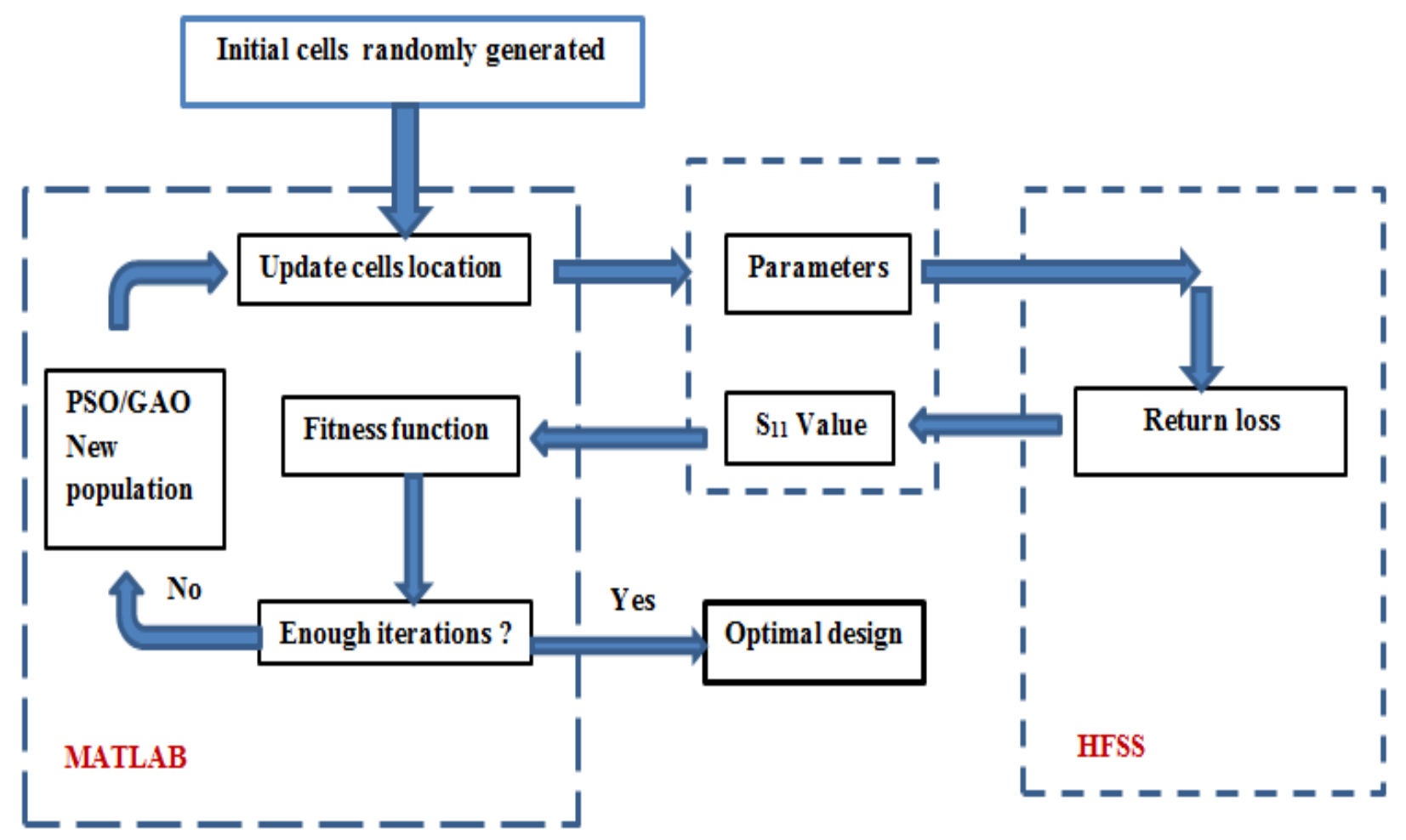

Fig.5: The combination block diagram of MATLAB with HFSS

A strategy for the combination of optimization algorithms (GA and PSO) with HFSS is illustrated in Fig.5. The optimization algorithms operations are compiled by HFSS. The calculation of fitness 
values is compiled by MATLAB. The design of PIFA antenna's ground plane is justified by a comparison with an evaluation of a fitness function. If the fitness meet requirement, the procedure is completed. Otherwise, those new structures are produced by a GA/PSO procedure. Those new structures are used in the next iteration for HFSS analysis to justify their performances.

\section{SIMULATION RESULTS AND COMPARISON}

\section{A. The simulated results obtained by $G A$}

The proposed PIFA antenna obtained by GA is shown in Fig.7. The optimal design of the ground plane (Fig.6) appears at the 200th iteration and has a configuration of:

\begin{tabular}{|l|l|l|l|l|l|l|l|}
\hline 0 & 1 & 0 & 0 & 0 & 0 & 0 & 1 \\
\hline 0 & 0 & 0 & 0 & 0 & 0 & 1 & 1 \\
\hline 1 & 0 & 0 & 0 & 1 & 1 & 0 & 1 \\
\hline 1 & 0 & 1 & 1 & 1 & 1 & 1 & 0 \\
\hline 0 & 0 & 0 & 1 & 0 & 0 & 0 & 1 \\
\hline 1 & 1 & 1 & 0 & 0 & 0 & 0 & 1 \\
\hline 0 & 1 & 1 & 0 & 1 & 1 & 1 & 0 \\
\hline
\end{tabular}

(a)

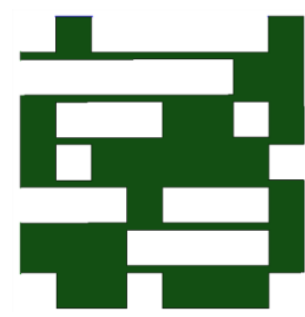

(b)

Fig.6: (a) Chromosome matrix, (b) Corresponding physical ground plane shape by using GA

The GA operates on a matrix chromosome, which describes the shape of the ground plane. This chromosome design is described in Fig. 6 (a). Matrix cells which contain a 1 correspond to portions of the antenna ground plane filled with metal; cells which contain a 0 correspond to portions of the antenna that are not filled as shown in Fig.6 (b).

It is observed that more than $50 \%$ of the ground plane is miniaturized.

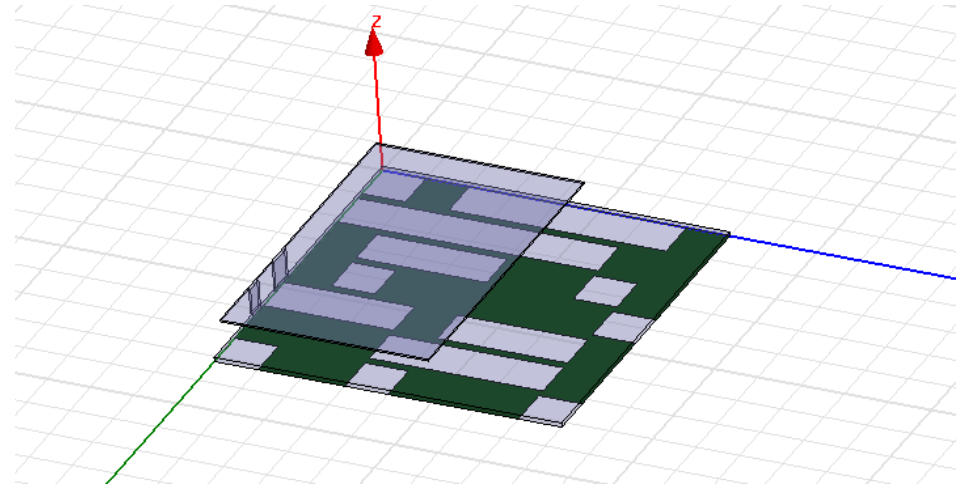

Fig.7: Optimal design of ground plane using GA

To show the influence of the slots on the ground plane, simulations of the ordinary PIFA without slots on the ground plane and the optimized PIFA with slots on the ground plane were plotted.

The simulated reflection coefficients of the proposed PIFA antenna with/without slots are presented in Fig.8.The maximum reflection coefficient and the bandwidths of the antenna without slots are respectively $-23.89 \mathrm{~dB}$ and $4.11 \%$ at $3.5 \mathrm{GHz}$.

On the other hand, we notice that the maximum reflection coefficient of the antenna with slots is $40.02 \mathrm{~dB}$ at $3.5 \mathrm{GHz}$, The upper and lower band frequencies are $3.324 \mathrm{GHz}$ and $4.002 \mathrm{GHz}$ respectively and the absolute impedance bandwidth is $677 \mathrm{MHz}$ and the bandwidth obtained for the 
proposed PIFA is $19.31 \%$. It can be seen that a new resonance frequency at $5.78 \mathrm{GHz}$ is added due to the slots on the ground plane.

In this case, we remark that, the slots ground planes have a double function. On one hand, it improves the bandwidth and reflection coefficient at resonate frequency. On the other hand, the slots are placed underneath the PIFA to create other bands to cover specific frequency band.

As shown in Fig. 9, the simulated 2D radiation patterns for the proposed PIFA at 3.5 and $5.78 \mathrm{GHz}$ are plotted. The patterns are improved with a maximum gain of about $2.58 \mathrm{~dB}$ for $3.5 \mathrm{GHz}$ and 5.65 $\mathrm{dB}$ for $5.78 \mathrm{GHz}$ compared to the simulated radiation of the initial antenna shown in Figure9 (a).

The simulated surface current distributions at different frequencies for the proposed PIFA are presented in Fig.10. As shown in Fig. 11, the real and imaginary components of the input impedance in the two resonant frequencies $(3.5 \mathrm{GHz}$ and $5.78 \mathrm{GHz})$ are around 50 and $0 \Omega$, respectively.

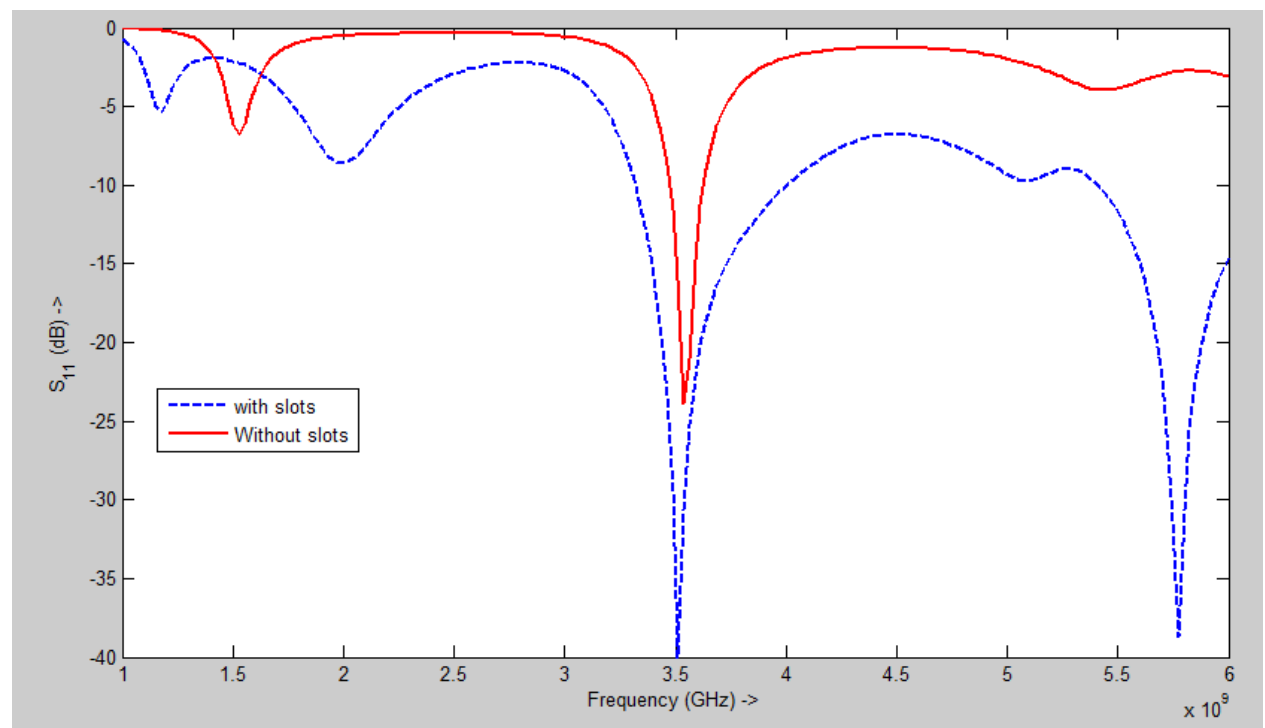

Fig.8: Simulated reflection coefficient of the antenna with /without slot on the ground plane using GA

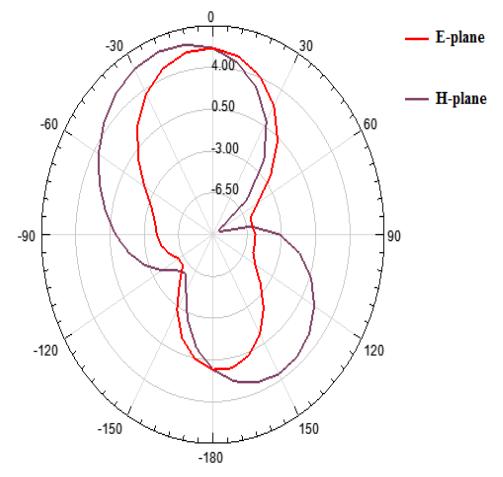

(a)

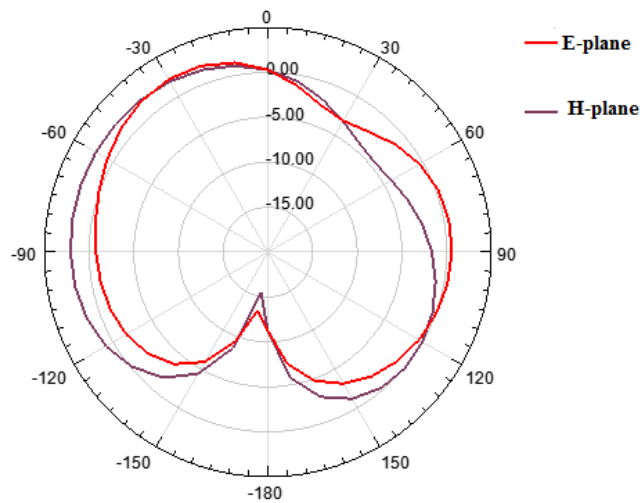

(b)

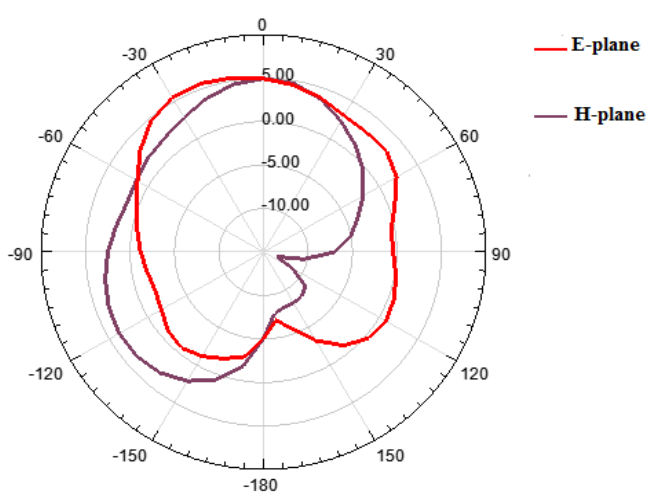

(c)

Fig.9: 2D Radiation pattern: (a) $3.5 \mathrm{GHz}$ antenna without slots,(b)and (c) are3.5GHz and 5.78GHzrespectively for proposed antenna using GA 


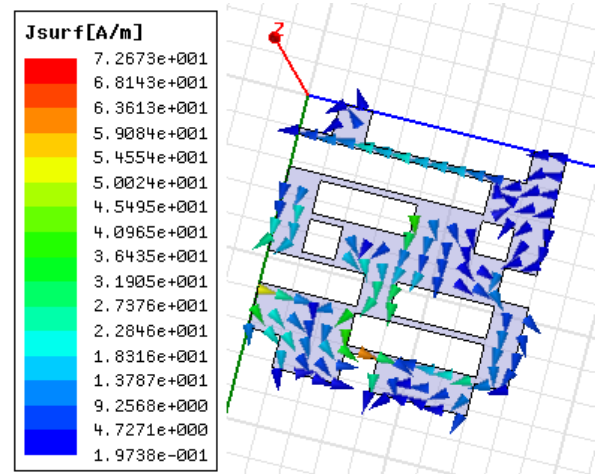

(a)

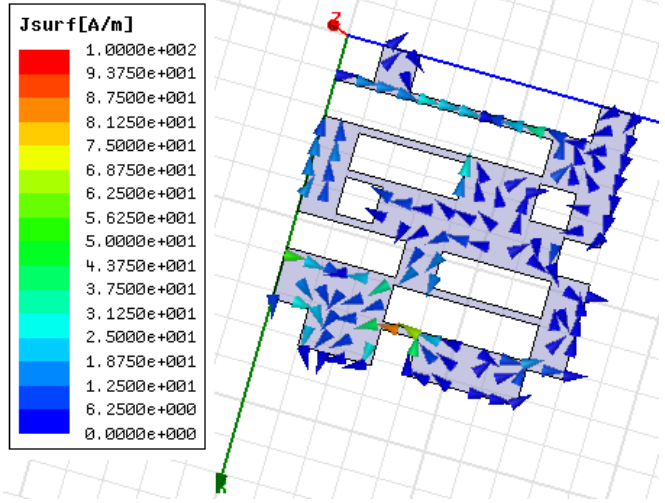

(b)

Fig.10: Current distributions in the ground plane shaped by GA at (a) $3.5 \mathrm{GHz}$ and (b) $5.78 \mathrm{GHz}$

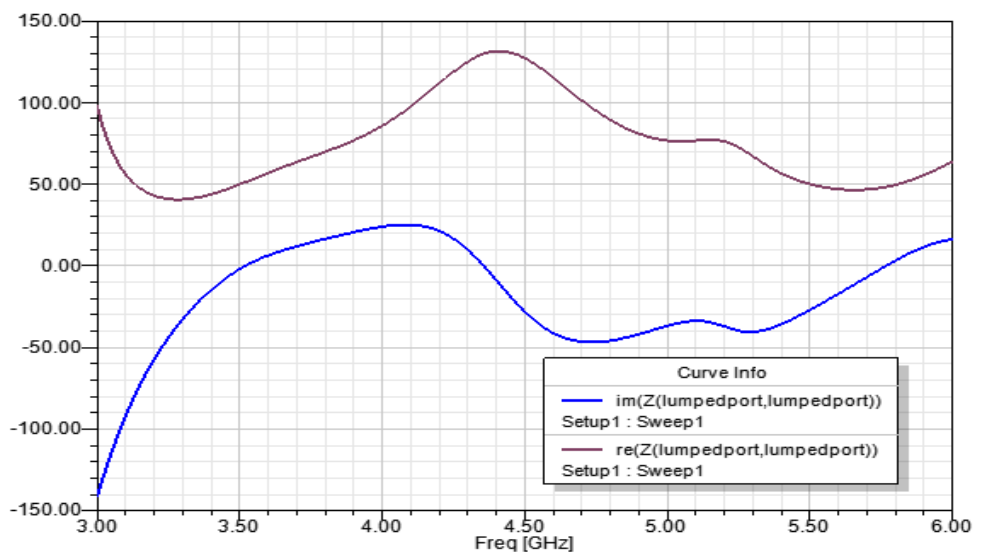

Fig.11: The input impedance $\mathrm{Z}$ in $\Omega$ versus frequency in GHz for the studied PIFA obtained by GA

\section{B. The simulated results obtained by PSO}

The PSO algorithm optimizes the reflection coefficient of PIFA antenna in the WiMAX bands and reduces the size of the ground plane compared to the size of the reference design. Through the 50 iterations, the PSO find the minimum size for the design (Fig.12 (b)) that has a configuration bellow (Fig.12 (a)):

\begin{tabular}{|l|l|l|l|l|l|l|l|}
\hline 0 & 1 & 0 & 1 & 0 & 1 & 0 & 0 \\
\hline 0 & 0 & 0 & 0 & 0 & 0 & 1 & 0 \\
\hline 1 & 1 & 0 & 0 & 1 & 1 & 0 & 1 \\
\hline 1 & 0 & 1 & 1 & 1 & 1 & 0 & 1 \\
\hline 0 & 0 & 0 & 1 & 1 & 1 & 1 & 0 \\
\hline 1 & 0 & 1 & 0 & 0 & 0 & 0 & 1 \\
\hline 1 & 0 & 1 & 0 & 1 & 1 & 0 & 0 \\
\hline
\end{tabular}

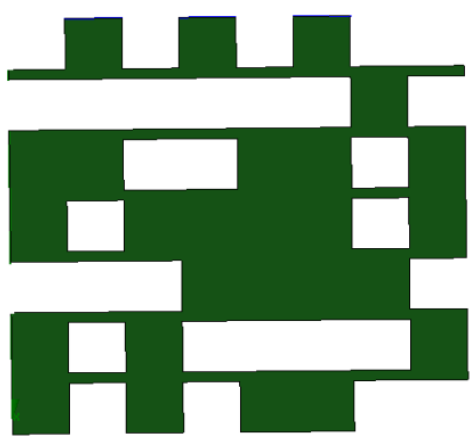

(a)

(b)

Fig.12: (a) Chromosome matrix, (b): Ground plane shape using PSO 


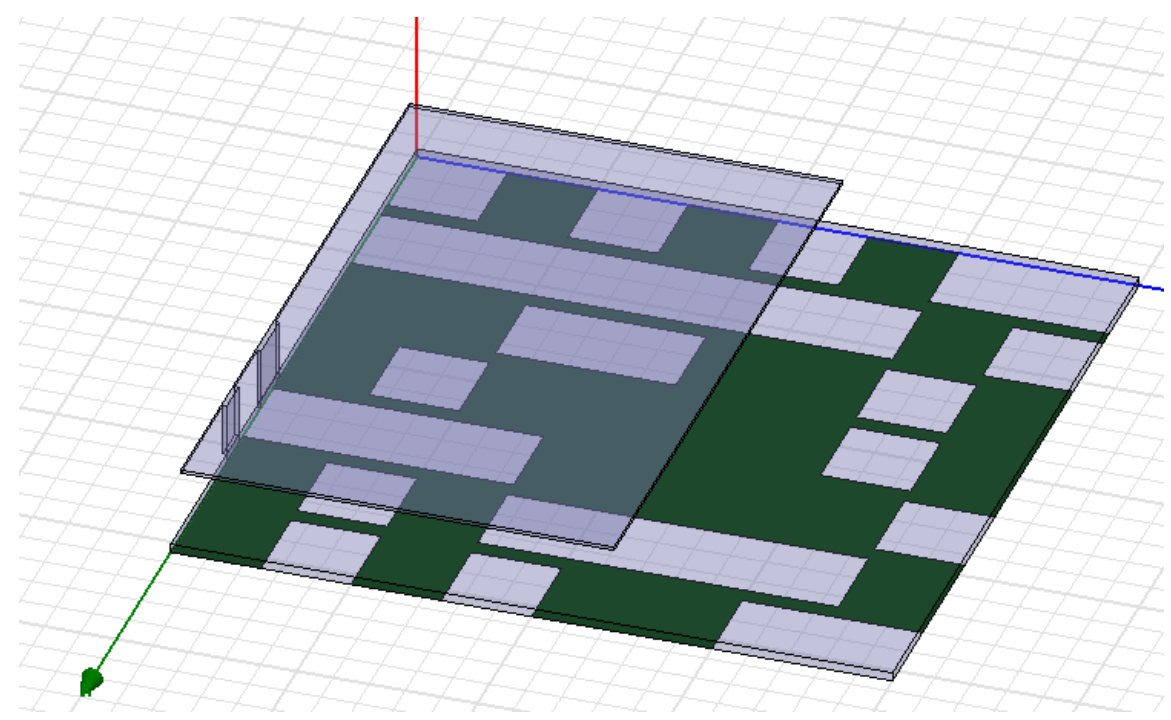

Fig.13: Geometry of the PIFA antenna obtained by PSO

As shown in Fig.13, the 53\% of the ground plane area was miniaturized by PSO.

The optimized antenna resonates at three frequencies $(3.5 \mathrm{GHz}, 4.76 \mathrm{GHz}$ and $5.62 \mathrm{GHz})$ within the WiMAX frequency band as shown in Fig.14. The slots are responsible for obtaining the perfect impedance matching in the WiMAX bands. The reflection coefficient is improved from $-25.65 \mathrm{~dB}$ to $32.66 \mathrm{~dB}$.

We notice also that new resonant frequencies appear at 4.76 and $5.62 \mathrm{GHz}$. The $-10 \mathrm{~dB}$ bandwidth reaches about $1070 \mathrm{MHz}(3.38-4.45 \mathrm{GHz})$. It increases by approximately from $4.11 \%$ to $30.57 \%$ at 3.5 $\mathrm{GHz}$; thereafter, we get wideband instead narrow band. It can be seen that a new band of resonance frequency at $5.78 \mathrm{GHz}$ is added due to the slots on the ground plane.

The radiation patterns of the PIFA design were also computed and the corresponding polar plots for each frequency band are shown in Fig. 15(a) and Fig.15 (b). As seen, the antenna exhibits almost omnidirectional radiation patterns over the bands of interest.

The simulated surface current distributions at different frequencies for the proposed PIFA are presented in Fig.16 (a) shows the current pattern at $3.5 \mathrm{GHz}$. The current pattern at $5.62 \mathrm{GHz}$ is given in Fig. 16(b). It can be seen that the current is distributed almost all over the surface of the ground plane.

As shown in Fig. 17, the real and imaginary components of the input impedance in the three resonant frequencies are around 50 and $0 \Omega$, respectively. 
Journal of Microwaves, Optoelectronics and Electromagnetic Applications, Vol. 15, No. 4, December 2016304 DOI: http://dx.doi.org/10.1590/2179-10742016v15i4626

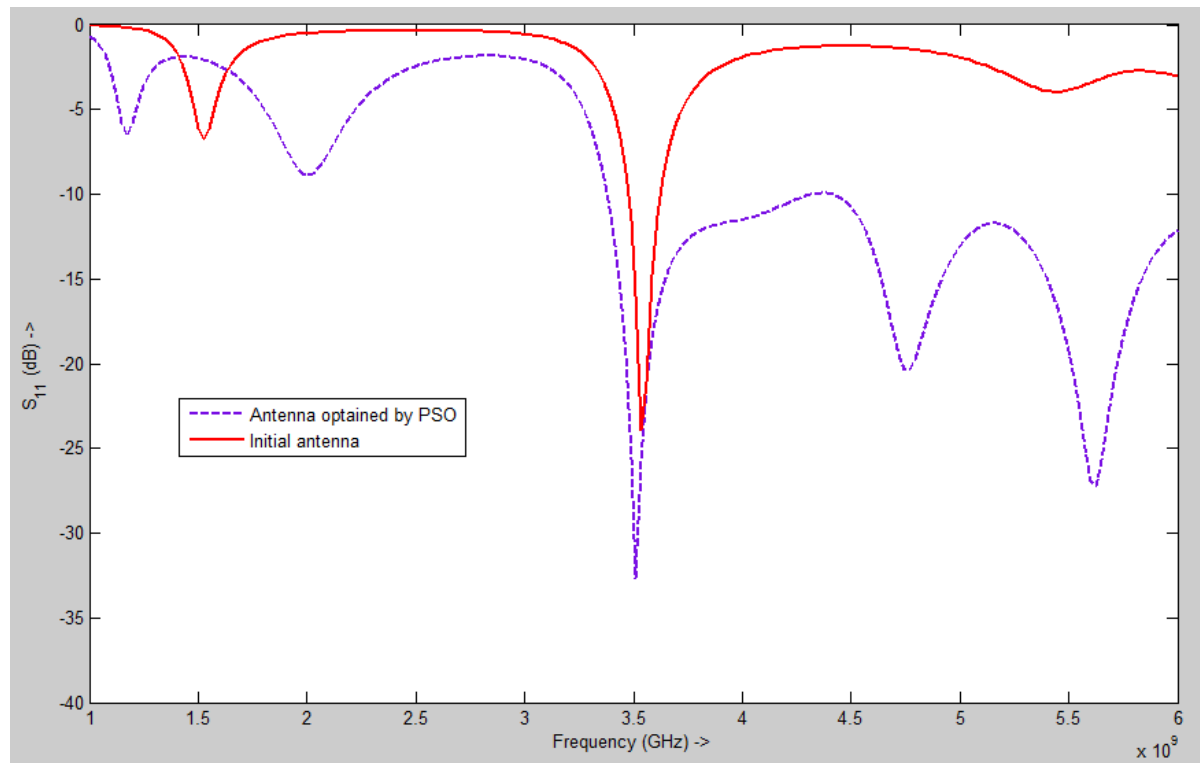

Fig.14: Simulated reflection coefficient of the initial antenna and obtained antenna by PSO

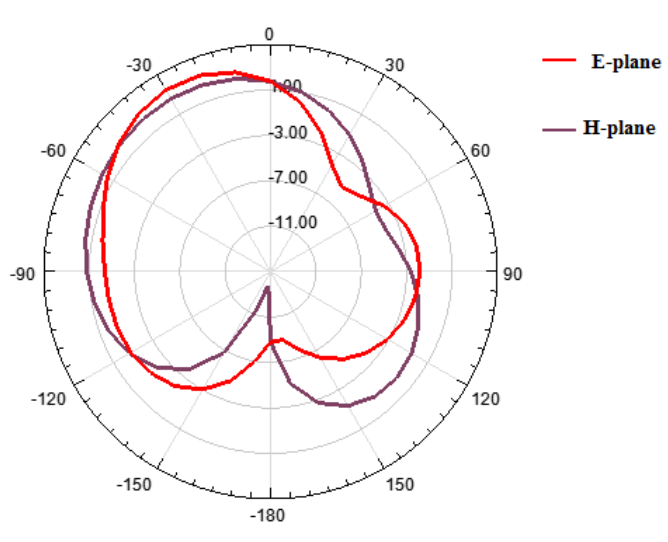

(a)

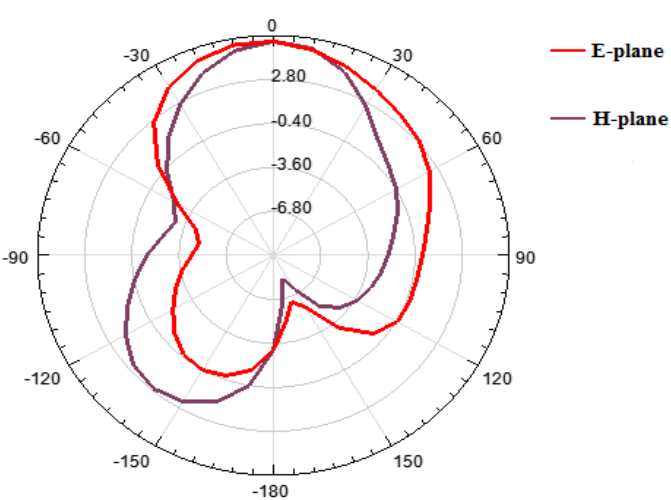

(b)

Fig.15: 2D Radiation pattern for antenna obtained by PSO: (a) $2 \mathrm{D}$ for $\mathrm{f}=3.5 \mathrm{GHz}$, (b) $2 \mathrm{D}$ for $\mathrm{f}=5.62 \mathrm{GHz}$

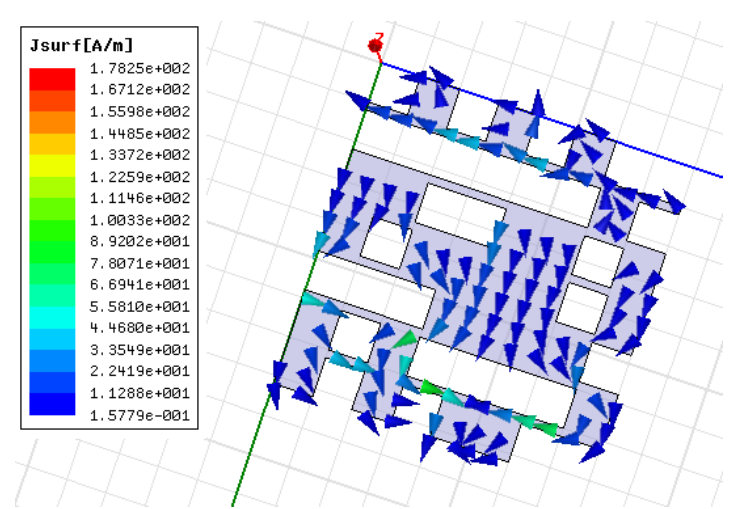

(a)

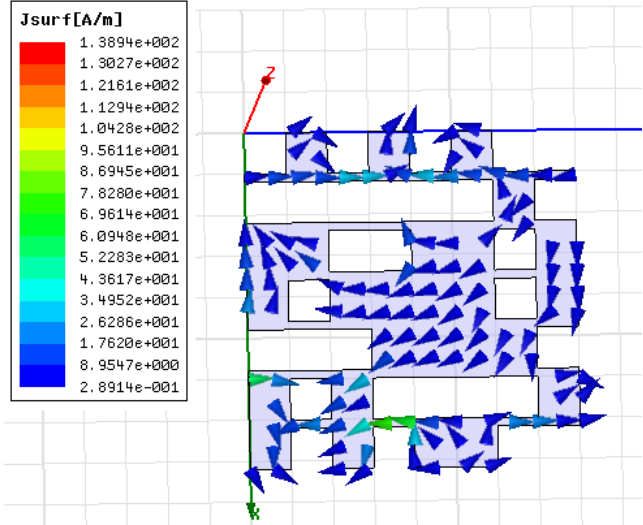

(b)

Fig.16: Current distributions in the ground plane shaped by PSO at (a) $3.5 \mathrm{GHz}$. (b) $5.62 \mathrm{GHz}$ 
Journal of Microwaves, Optoelectronics and Electromagnetic Applications, Vol. 15, No. 4, December 2016305 DOI: http://dx.doi.org/10.1590/2179-10742016v15i4626

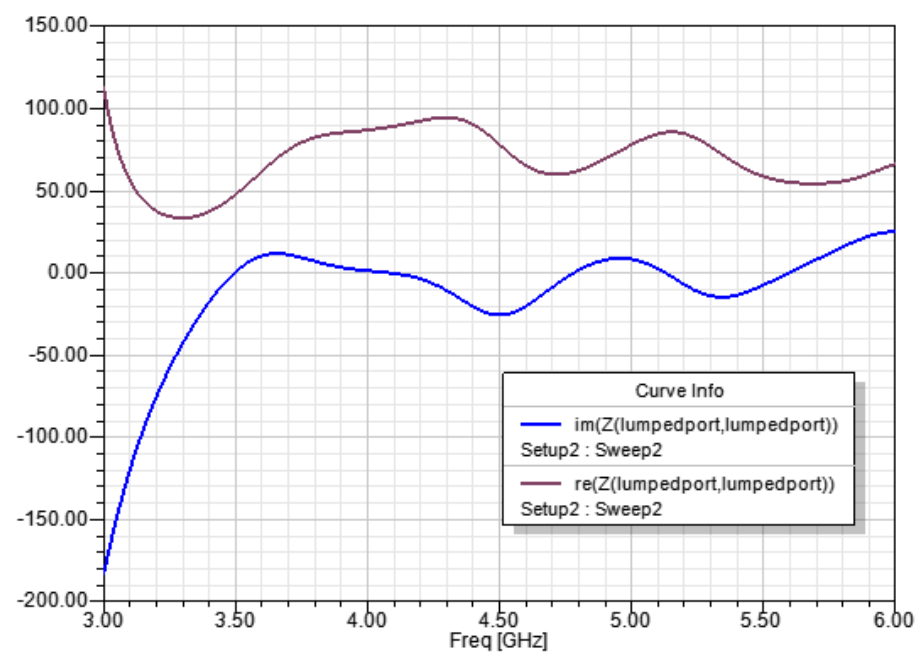

Fig. 17: The input impedance $Z$ in $\Omega$ versus frequency in GHz for the PIFA obtained by PSO

As a solution, the use of gridded ground plane with overlapping cells is proposed in this paper, GA and PSO find the best ground plane geometry with improved performance more effectively. A comparison of the reflection coefficient over frequency in the optimized designs are shown in Fig.18. We can easily visualize from these plots that a significant improvement in bandwidth has been achieved with the proposed new ground plane for the low-frequency band as well as for the highfrequency band. PSO and GA give similar geometry and show a correlation of $82.34 \%$.

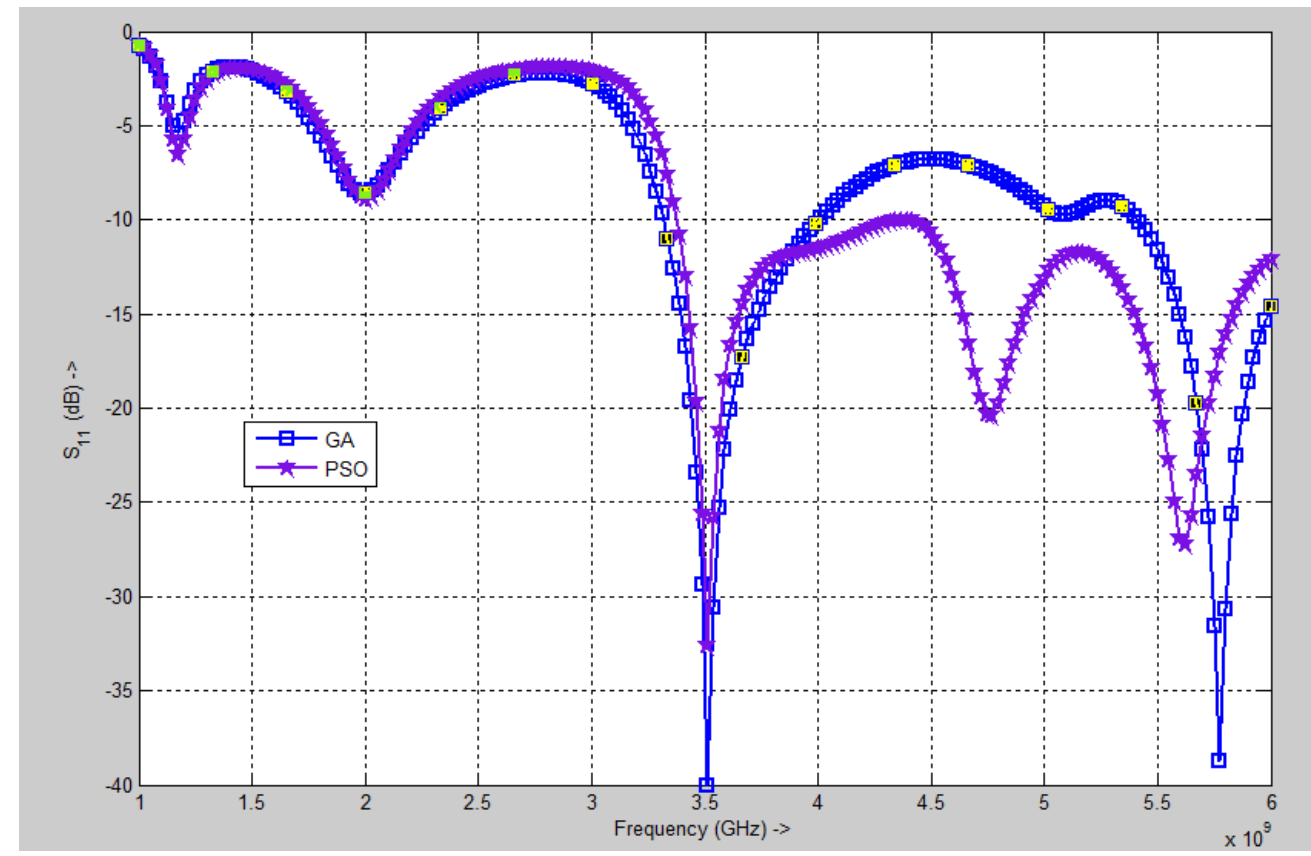

Fig.18: Simulated reflection coefficient for the optimized antenna obtained by GA and PSO

We can summarize the results given by PSO and GA in the Table III as bellow: 
Journal of Microwaves, Optoelectronics and Electromagnetic Applications, Vol. 15, No. 4, December 2016306 DOI: http://dx.doi.org/10.1590/2179-10742016v15i4626

TABLE III.NUMERICAL VALUES OF THE BANDWIDTH, REFLECTION COEFFICIENT, GAIN FOR THE OPTIMIZED AND REFERENCED

\begin{tabular}{clcccc}
\hline Antenna & \multicolumn{2}{c}{ Resonant frequency $(\mathbf{G H z})$} & Bandwidth $(\boldsymbol{\%})$ & $\mathbf{S}_{\mathbf{1 1}}(\mathbf{d B})$ & Gain $(\mathbf{d B})$ \\
\hline Reference antenna & & 3.5 & 4.11 & -23.89 & 6.37 \\
\hline GA & $\mathrm{f}_{1}=3.5$ & 19.31 & -40.02 & 2.58 \\
& $\mathrm{f}_{2}=5.78$ & 16.14 & -38.74 & 5.65 \\
\hline \multirow{2}{*}{ PSO } & $\mathrm{f}_{1}=3.5$ & 30.57 & -32.66 & 3.55 \\
& $\mathrm{f}_{2}=5.62$ & 37.90 & -27.27 & 5.57 \\
& & & & \\
\hline
\end{tabular}

In this paper, we propose a slotted ground plane that can effectively reduce the PIFA weight by more than $50 \%$, improve the bandwidth and introduce more frequency band.

TABLE IV: COMPARISON OF THE RESULTS AND OTHERS GIVEN BY LITERATURE

\begin{tabular}{|c|c|c|c|c|}
\hline Paper & Antenna type & Method & $\begin{array}{c}\text { Hight of } \\
\text { antenna }(\mathbf{m m})\end{array}$ & Results \\
\hline [30] & $\begin{array}{l}\text { Single and dual PIFA } \\
\text { antenna }\end{array}$ & $\begin{array}{l}\text { Meander-shaped } \\
\text { ground plane }\end{array}$ & $h=4$ & $\begin{array}{l}\text { - } \quad \text { Reduce the } \\
\text { hight of } \\
\text { antenna by } \\
50 \%\end{array}$ \\
\hline [31] & $\begin{array}{l}\text { Mono band PIFA } \\
\text { antenna }\end{array}$ & $\begin{array}{l}\text { Open-end parallel } \\
\text { slots in the ground } \\
\text { plane }\end{array}$ & $h=6$ & $\begin{array}{l}\text { Reduce the } \\
\text { volume of the } \\
\text { antenna } \\
\text { - } \quad \text { Bandwidth } \\
\text { enhancement }\end{array}$ \\
\hline [32] & $\begin{array}{l}\text { Dual band PIFA } \\
\text { antenna }\end{array}$ & $\begin{array}{l}\text { U shape slot on the } \\
\text { ground plane }\end{array}$ & $\mathrm{h}=6$ & $\begin{array}{c}\text { - } \quad \text { Bandwidth } \\
\text { improved }\end{array}$ \\
\hline [33] & $\begin{array}{c}\text { Multiband PIFA } \\
\text { antenna }\end{array}$ & $\begin{array}{l}\text { Two slots on the } \\
\text { ground plane }\end{array}$ & $\mathrm{h}=1.27$ & $\begin{array}{c}\text { Bandwidth } \\
\text { enhancement }\end{array}$ \\
\hline Our research & $\begin{array}{l}\text { Dual band PIFA } \\
\text { antenna }\end{array}$ & $\begin{array}{c}\text { Gridded ground } \\
\text { plane combined with } \\
\text { GA/PSO }\end{array}$ & $\mathrm{h}=3$ & $\begin{array}{l}\text { Reduce the } \\
\text { ground plane } \\
\text { shape by more } \\
\text { than } 50 \% \\
\text { - } \quad \text { Produce new } \\
\text { resonant } \\
\text { frequency } \\
\text { - Enhance the } \\
\text { bandwidth }\end{array}$ \\
\hline
\end{tabular}

Table IV presents some papers in literature that studying the effect of the slots on the ground plane. Result in [30] and [31] shows using slots on the ground plane can reduce the volume of antenna. [32] and [33] present using slotted ground plane to broadening the bandwidth. In this work, a PIFA antenna with slots on the ground plane is used. These slots are optimized in dimensions and positions by GA then by PSO, to cover the desired frequencies and to improve the bandwidth. Our approach propose slotted ground plane as solution to achieve dual band antenna, to allow for reducing the antenna volume without changing the geometrical shape of the radiating element and to enhance the bandwidth. 


\section{CONCLUSION}

Using slotted ground plane is a simple way to achieve a multiband antenna without modifying PIFA antenna geometry and increasing the handset volume. In this paper, genetic algorithm and particle swarm optimization techniques were used to find the optimal slotted geometry of the ground plane that satisfy these criteria.

Both antennas given by PSO and GA, show similar geometry and a good correlation coefficient of $82.34 \%$. Comparing the antenna with and without slotted ground plane obtained by PSO and GA, bandwidth has been improved at low frequency and new band appear at high frequency.

Therefore, a dual band antenna with good bandwidth and efficiency response was obtained by using fragmented ground plane and evolutionary algorithms (GA and PSO). Since the mobile phone industry requires small handset terminals with internal antennas, the proposed technique in this research is a good way to reach these requirements.

\section{REFERENCES}

[1] S.Ibnyaich, A.Ghammaz And M.M.Hassani (December,2012),” Planar Inverted-F Antenna With J-Shaped Slot And Parasitic Element For Ultra-Wide Band Application", International Journal Of Microwave And Wireless Technologies, Vol.4, Issue 6, pp: 613-621, DOI: http://dx.doi.org/10.1017/S175907871200058X

[2] Mohammad R. Ameerudden, And Harry C. S. Rughooputh,( July, 2014), "Smart Hybrid Genetic Algorithms In The Bandwidth Optimization Of APIFA Antenna", 2014 IEEE Congress On Evolutionary Computation (CEC), Beijing, China. DOI: 10.1109/CEC.2014.6900394

[3] L.Wakrim, S.Ibnyaich, M. M.Hassani (March 2016)"Novel Miniaturized Multiband and Wideband PIFA “, 3rd International Conference on Automation, Control Engineering and Computer Science, Proceeding of Engineering \& Technology, pp:66-70

[4] L.Wakrim, S.Ibnyaich, M.M.Hassani, (April,2014)," Optimization by genetic algorithm of a PIFA antenna parameters for Wifi application", International conference on Multimedia and computing, pp: 1501 - 1505, DOI: 10.1109/ICMCS.2014.6911223

[5] R. A. Khudan, J. S. Aziz,(2013) 'Design And Implementation Of Miniaturized Antennas For Wireless Sensor Network Applications Using Particle Swarm Optimization", International Journal Of Electromagnetics And Applications , 3(4): pp: 81-95

[6] T. B. Chen, Y. L. Dong, Y. C. Jiao, And F. S. Zhang,(2006)“Synthesis Of Circular Antenna Array Using Crossed Particle Swarm Optimization Algorithm", J. Of Electromagn. Waves And Appl., Vol. 20, No. 13, 1785-1795,

[7] Yogesh choukiker, S K Behera, D Mishra, R K Mishra,(December 2009) "Optimization Of Dual Band Microstrip antenna Using PSO”, IEEE Applied Electromagnetic Conference (AEMC), Calcutta,pp:1-4, DOI: 10.1109/AEMC.2009.5430685

[8] Nanbojin, Yahyarahmat-Samii, (November 2005), "Parallel Particle Swarm Optimization And Finitedifference Time-Domain (PSO/FDTD) Algorithm For Multiband And Wide-Band Patch Antenna Designs", IEEE Transactions On Antennas And Propagation, Vol. 53, No. 11, pp:3459 - 3468, DOI: 10.1109/TAP.2005.858842

[9] Lizzi, L. ; Viani, F.; Azaro, R. ; Massa, A.( 2007), "Optimization Of A Spline-Shaped UWB Antenna By PSO", Antennas And Wireless Propagation Letters, IEEE (Volume:6 ),pp $182-185$

[10] Wen-Chung Liu ,( Oct. 2005 ), "Design Of A Multiband CPW-Fed Monopole Antenna Using A Particle Swarm Optimization Approach”, IEEE Transactions OnAntennas And Propagation, (Volume:53, Issue: 10 ), pp 3273 - 3279

[11] Shweta Rani,A.P. Singh, (2013) “On The Design And Optimisation Of New Fractal Antenna Using PSO”, International Journal Of Electronics ,Volume 100, Issue 10, pp 1383-1397

[12] TrongDucNguyena, Yvan Duroca, Van YemVua and Tan PhuVuonga, ,( December 2011), "Genetic algorithm for optimization of Lshaped PIFA antennas", International journal of Microwave and Wireless Technology, vol.3, Issue 6, pp: 691-699

[13] L.Wakrim, S.Ibnyaich, M.M.Hassani, (November 2014) " Conception Of PIFA Antenna by Multiobjective Optimization Using Genetic Algorithm for WiMAX Application at $3.5 \mathrm{GHz}$ ", The eighth edition of International Symposium on signal, Image, Video and Communications (ISIVC'14)

[14] T.Mori, R.Murakami,Y.sato,F,Campelo, (2015) "Shape Optimization of Wideband Antennas for Microwave Energy Harvesters Using FDTD", IEEE Transactions on Magnetics ,Volume 51, Issue 3.

[15] C. Picher, J. Anguera,( 2009)," Multiband Handset Antenna Using Slot On The Ground Plane: Considerations Tofacilitate The Integration Of The Feedingtransmission Line” Progress In Electromagnetics Research C, Vol. 7,pp: 95-109.

[16] R. Hossa, A. Byndas, And M. E. Bialkowski ,(June 2004), "Improvement Of Compact Terminal Antenna Performance By Incorporating Open-End Slots In Ground Plane” IEEE Microwave And Wireless Components Letters, Vol. 14, No. 6.

[17] Arnaucabedo, Jaumeanguera, Cristina Picher, Miquelribó,Carles Puente, (,September 2009) « Multiband Handset Antenna Combining A PIFA, Slots, And Ground Plane Modes", IEEE Transactions On Antennas And Propagation, Vol. 57, No. 9, pp: 2526-2533

[18] Sinhyung Jeon, Hyengcheul Choi, And Hyeongdong Kim, (October 2009 ) "Hybrid Planar Inverted-F Antenna With A T-Shaped Slot On The Ground Plane" ETRI Journal, Volume 31, Number 5, pp 616-618

[19] M. Rostamzadeh, S. Mohamadi, J. Nourinia, Ch. Ghobadi, And M. Ojaroudi, (2012) " Square Monopole Antenna For UWB Applications With Novel Rod-Shaped Parasitic Structures And Novel V-Shaped Slots In The Ground Plane" IEEE Antennas And Wireless Propagation Letters, Vol. 11, pp 446-449

[20] R. Hossa, A. Byndas, And M. E. Bialkowski , (June 2004 ) “Improvement Of Compact Terminal Antenna Performance By Incorporating Open-End Slots In Ground Plane", IEEE Microwave And Wireless Components Letters, Vol. 14, No. 6, pp 283-285

[21] YahyaRahmat-Samii , (October 2003 ) "Genetic Algorithm (GA) And Particle Swarm Optimization (PSO) In Engineering Electromagnetics", $17^{\text {th }}$ International Conference On Applied Electromagnetics And Communications. Dubrovnik, Croatia 
Journal of Microwaves, Optoelectronics and Electromagnetic Applications, Vol. 15, No. 4, December 2016308 DOI: http://dx.doi.org/10.1590/2179-10742016v15i4626

[22] David W. Coit, Alice E. Smith, (june 1996), " Reliability Optimization Of Series-Parallel Systems Using A Genetic Algorithm", IEEE Transactions On Reliability, Vol. 45. No. 2,

[23] J. Michael Johnson, YahyaRahmat-Samii, (1997) "Genetic Algorithms In Engineering Electromagnetics", IEEE Antennas And Propagation Magazine (Volume: 39, Issue: 4), Pages 7-21.

[24] Mohammad Shihab , Yahyanajjar, Nihad Dib , Majid Khodier ,(2008)," Design Of Non-Uniform Circular Antenna Arrays Using Particle Swarm Optimization", Journal Of Electrical Engineering, Vol. 59, No. 4,pp:216-220

[25] Dennis Gies, Yahyarahmat-Samii , (August 2003)“Particle Swarm Optimization For Reconfigurable Phase differentiated Array Design", Microwave And Optical Technology Letters / Vol. 38, No. 3, pp: 168-175

[26] W. T. Li And X. W. Shi ,(2008), “An Improved Particle Swarm Optimization Algorithm For Pattern Synthesis Of Phased Arrays”, Progress In Electromagnetics Research, Pier 82, 319-332

[27] Wen-Chung Liu (October 2005), “ Design Of A Multiband Cpw-Fed Monopole Antenna Using A Particle Swarm Optimization Approach”, IEEE Transactions On Antennas And Propagation, Vol. 53, No. 10, pp: 3273-3279

[28] Douglas H. Werner, P. L. Werner, Douglas H. Werner, 2006,“The Design Of Miniature Three-Element Stochastic Yagi-Uda Arrays Using Particle Swarm Optimization", IEEE Antennas And Wireless Propagation Letters, Vol. 5, pp:22-26

[29] C.H. See, R.A. Abd-Alhameed, D. Zhou, H.I. Hraga, P.S. Excell,2011, " Broadband Dual Planar Inverted F-Antenna For Wireless Local Area Networks/Worldwide Interoperability For Microwave Access And Lower-Band Ultra Wideband Wireless Applications", Microwaves, Antennas \& Propagation, Iet (Volume:5, Issue: 6 ), pp: $644-650$.

[30] M. F. Abedin And M. Ali,2003, "Modifying The Ground Plane And Its Effect On Planar Inverted-F Antennas (PIFAs) For Mobile Phone Handsets", IEEE Antennas And Wireless Propagation Letters, Vol. 2,

[31] R. Hossa, A. Byndas, And M. E. Bialkowski, June 2004, "Improvement Of Compact Terminal Antenna Performance By Incorporating Open-End Slots In Ground Plane", IEEE Microwave And Wireless Components Letters, Vol. 14, No. 6

[32] C. Picher And J. Anguera, 2009, ” Multiband Handset Antenna Using Slots On The Ground Plane: Considerations To Facilitate The Integration Of The Feeding Transmission Line", Progress In Electromagnetics Research C, Vol. 7, 95-109.

[33] Li-Jie Xu, Yong-Xin Guo, Wen Wu, 2012," Dual-Band Implantable Antenna with Open-End Slots on Ground”, IEEE Antennas And Wireless Propagation Letters, Vol. 11,pp 1564 - 1567 